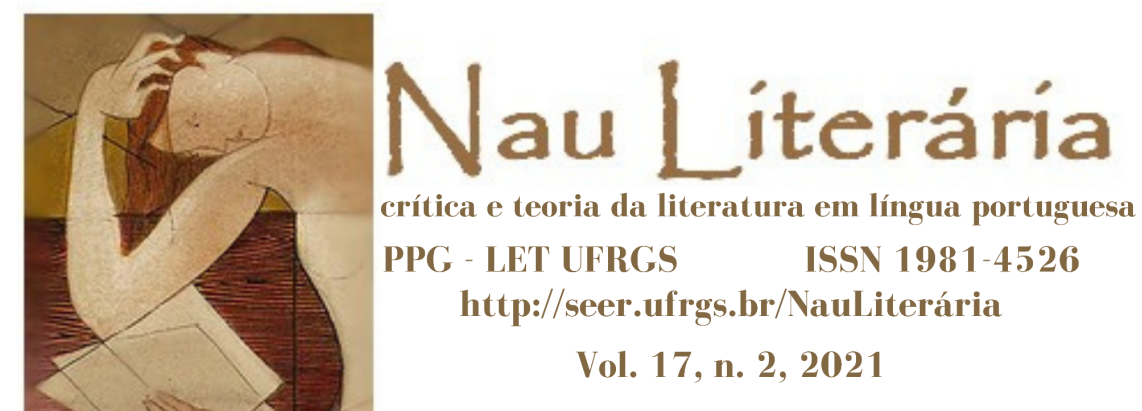

CHAGAS, Pedro Dolabela. Todos eles romances: a variação do gênero no Brasil, 1960-1980. Campinas: Editora da Unicamp, 2020. 408 p.

\title{
Estes anos 1970: um panorama sobre a complexidade do romance brasileiro contemporâneo
}

\section{Suelen Ariane Campiolo Trevizan ${ }^{1}$}

É recorrente que análises sobre a ficção brasileira produzida nos anos 1970 dialoguem muito de perto com o contexto político, dado que essa década decorreu inteira num regime de ditadura militar. Embora esse tipo de interpretação seja relevante, sua predominância pode tornar a pesquisa acadêmica cega para os aspectos das obras que não caibam nessa chave de leitura. Todos eles romances: a variação do gênero no Brasil, 1960-1980, de Pedro Dolabela Chagas, nasce do desejo de descrever a complexidade desses romances, observando a variedade de questões e abordagens que se prolifera no período, além de mudanças no campo literário em geral. Alinhado ao paradigma rizomático de Deleuze e Guattari, esse panorama não elege um eixo central, mas aponta simultaneidades.

Sua ênfase, como o título explicita, recai sobre o gênero romance, e é com romances que esse livro lida. Tal afirmação não soará tão redundante se considerarmos que tantos estudos panorâmicos preferem se deter na generalização de características das obras, no contexto histórico ou na revisão da recepção crítica, sem entrar propriamente no embate com os textos literários. Um provável modelo historiográfico para a pesquisa de Chagas parece ser a tese de Luís Bueno, Uma história do romance de 30, que questiona certa tendência a considerar a produção dessa década como sinônimo de narrativa regionalista. Para fugir ao senso comum, é preciso conhecer aquilo que se pretende descrever, então Bueno fez uma leitura extensa de romances desse período, não só dos canônicos. Do mesmo modo, Chagas procura resgatar obras que não necessariamente são as mais lembradas ou, mesmo que o

\footnotetext{
${ }^{1}$ Doutoranda em Estudos Literários pela Universidade Federal de Minas Gerais (UFMG), bolsista Capes.
} 


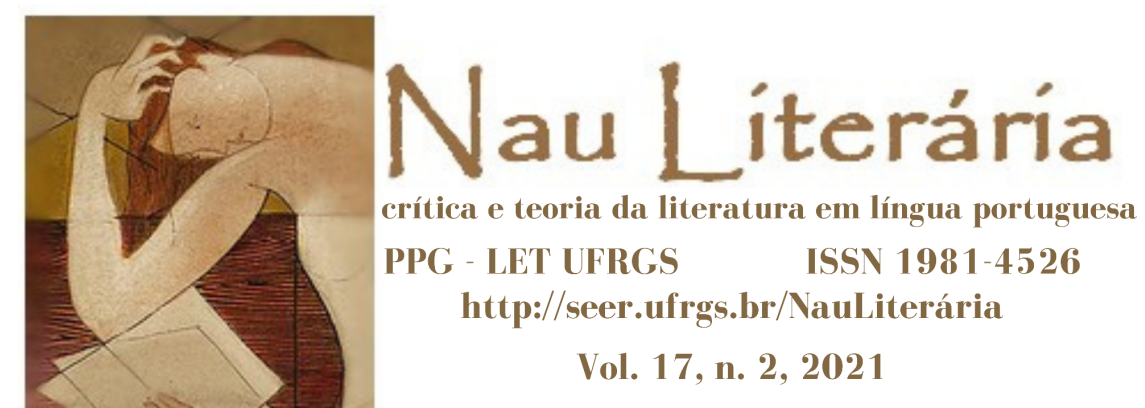

sejam, não deixaram uma filiação literária expressiva. É o caso, por exemplo, de Avalovara, de Osman Lins, cuja excepcionalidade não se explica facilmente pelo contexto sociopolítico.

Antes de entrar na leitura dos romances, o primeiro capítulo explicita o que se entende por esse gênero e qual é a metodologia da pesquisa. Chama a atenção logo de saída o vocabulário relacionado ao evolucionismo literário, perspectiva teórica pouco disseminada na academia brasileira $^{2}$. Essa abordagem observa a literatura como sistema autônomo, e nesse contexto as obras surgem como fatores de ação e conservação. "É em atenção às convenções da tradição literária e às operações de um sistema auto-organizado, que as variações individuais das obras permitem que o romance, como gênero, se adapte continuamente a condições ambientais cambiantes.” (CHAGAS, 2020, p. 35). Segundo esse modelo de análise, se os romances apresentam inovações, que podem ser bem ou mal recebidas pelo público, essas são tentativas de adaptação sem uma direção definida, que visam, acima de tudo, a própria conservação do sistema. Apenas a longo prazo se pode avaliar essas participações individuais na cena mais ampla.

A hipótese de Chagas é que, por volta da década de 1970, teria havido uma "bifurcação histórica", isto é, um processo de "reacomodação" do sistema, de modo que se tornaram corriqueiras práticas que não poderiam ser imaginadas antes desse período, mas que já estavam lá de modo latente ${ }^{3}$. Para descrever essa dobra, o pesquisador usa duas técnicas próprias à taxonomia, reforçando sua relação com o léxico darwinista: identifica splittings (diferenciação de semelhantes) e lumpings (aproximação de diferentes), movimentos realizados respectivamente nos capítulos 3 e 4 .

Delimitado o problema e a hipótese, Chagas passa a comentar mais detidamente diversos romances situados principalmente no período de 1967 a 1979, em que identifica o referido processo de complexificação da produção literária brasileira. Contudo, a primeira

\footnotetext{
${ }^{2}$ As primeiras publicações brasileiras especializadas nessa vertente teórica foram lançadas por um grupo de pesquisadores ao qual Chagas se inclui: os dois dossiês "Literatura e Teoria da Evolução" da revista Eutomia, v. 1, n. 15 (2014) e v. 1, n. 16 (2015).

${ }^{3}$ A expressão "latente" indica um diálogo produtivo com o trabalho de Hans Ulrich Gumbrecht, ex-orientador de Chagas na Universidade de Stanford. Cf. GUMBRECHT, 2014.
} 


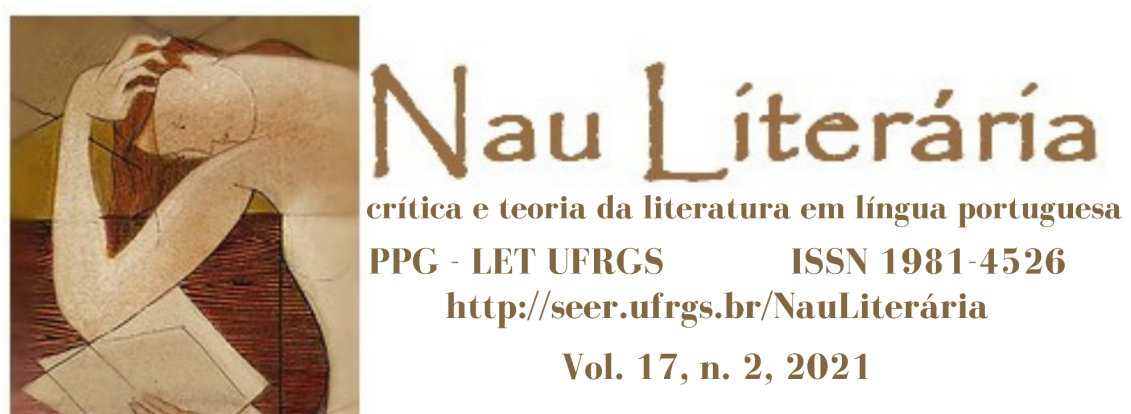

obra sobre a qual ele se debruça, no capítulo 2 , é anterior a esse intervalo - refiro-me a Grande sertão: veredas. Esse recuo para a década de 1950 ajuda a entender o começo da mudança, quando essa ainda estava latente: "ali se demarcava uma dobra no tempo, na qual elementos daquilo que em breve se tornaria passado ainda ocupavam o proscênio, enquanto as linhas de condução do futuro próximo ganhavam presença e legitimação" (CHAGAS, 2020, p. 74). Mesmo a fortuna crítica rosiana sendo tão extensa, a leitura atenta de Chagas extrapola os lugares comuns. Sua principal contribuição é refletir sobre a posição de Grande sertão: veredas em relação à tradição (à qual se inclui o romance de 30) e à transformação latente.

Após a "obra-monumento" de Guimarães Rosa, outros romances igualmente ambiciosos se multiplicariam nas décadas seguintes: Quarup, Incidente em Antares, Romance da Pedra do Reino, Zero, A festa, O minossauro, Catatau. São narrativas cujo escopo da representação é colossal, já que propõem descrições amplas de um Brasil em transformação. Essas obras "de impulso épico" são a linha a que Chagas dedica mais atenção, mais de cem páginas, observando a estratégia singular com que cada uma interpreta as novidades do presente à luz da história nacional. Outros títulos observados de perto são aqueles lançados na segunda metade da década de 1970 e que, mais ou menos próximos à forma tradicional do romance, já apresentam alguns consensos sobre a interpretação nacional (Lúcio Flávio, Essa terra, Cabeça de Negro, A rainha dos cárceres da Grécia, Galvez, imperador do Acre). Por fim, comentam-se ainda os que já não tratam do Brasil como questão principal (Avalovara, Deus de Caim, Confissões de Ralfo, Armadilha para Lamartine, Pilatos, Limite branco, A paixão segundo G. H.).

Essa parte da pesquisa que descreve as obras separadamente (capítulo 3) apresenta exercícios instigantes de crítica literária, tornando a diversidade do terreno mais explícita para o leitor antes de propor generalizações no capítulo posterior. Como ressalva, fica apenas um estranhamento quanto à irregularidade das análises, em extensão e aprofundamento. Parece haver um interesse maior em descrever o primeiro grupo, aquele em que a problematização de um novo contexto nacional se coloca de modo mais evidente. Quando se chega ao terceiro 


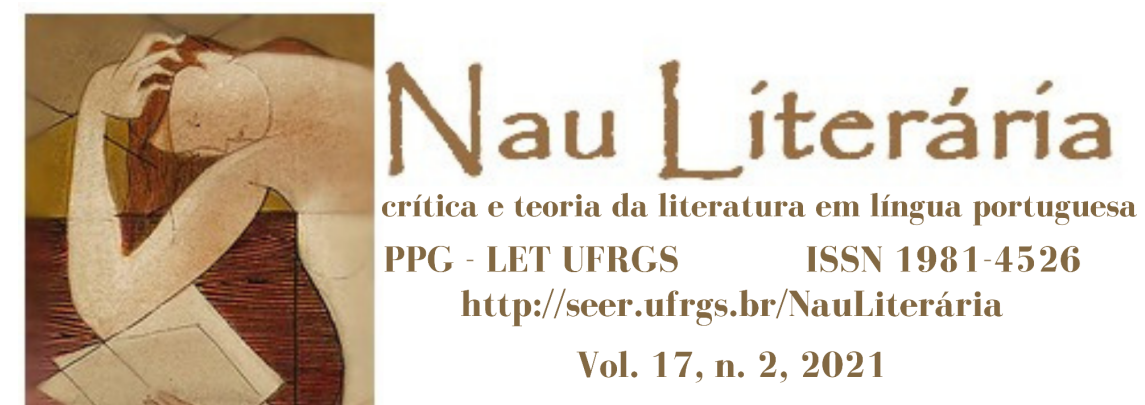

conjunto, a excelente análise de Avalovara ${ }^{4}$ ocupa quase 30 páginas, enquanto os outros seis romances disputam entre si cerca de 15 páginas. Assim, essa vertente da literatura que se afasta da discussão da nacionalidade, apesar de ser uma tendência forte na contemporaneidade, aparece sub-representada no capítulo.

No seguinte (capítulo 4), em que se propõem novos critérios de rearranjo dos grupos, agora enfatizando as características em comum, observamos uma obra desse terceiro grupo, Pilatos, retornar numa passagem igualmente breve, mas agora lido sob a perspectiva do humor. A repetição seria descuido do autor? Dificilmente. Parece, isso sim, ser um modo de explicitar que, sendo um corpus literário complexo, comporta olhares múltiplos - aquilo que Chagas já havia apontado acerca da novidade de Grande sertão: veredas.

Nesse rearranjo, o número de títulos mencionados cresce em relação ao capítulo anterior - aqui a metodologia quantitativa se sobrepõe à qualitativa na busca por generalizações -, além de se esboçar uma continuidade dos aspectos destacados para além do período estudado. Alguns romances mais recentes são citados, mas a análise desses não chega a ser realizada, o que se apresenta como um convite para pesquisas futuras. $\mathrm{O}$ autor propõe cinco critérios de agrupamento (lumping) das obras: realismo; delectare; romantismo; autonomia sistêmica; e o Brasil interpretado. Pelos nomes atribuídos às categorias, já se pode observar que são considerados aspectos formais, temáticos, sistêmicos e até ideológicos desses romances.

A palavra chave é, lembremos, complexidade. Como essa ocorre em vários níveis, assim também é a descrição de Chagas. Um dos pontos altos de sua abordagem teórica, a nosso ver, é olhar para o romance não como um objeto de valor inerente, mas em seu contexto de produção, circulação e recepção. Se essa sistematização às vezes parece pouco clara,

\footnotetext{
${ }^{4}$ A atenção dada à obra de Osman Lins, único autor que tem dois romances mais longamente comentados, Avalovara e A rainha dos cárceres da Grécia, talvez seja apenas reflexo do gosto pessoal do pesquisador, mas certamente faz um importante trabalho de resgate do escritor pernambucano, menos comentado que outros contemporâneos seus, como Rubem Fonseca, Lygia Fagundes Telles e Clarice Lispector, como se pode rapidamente constatar no número de menções na plataforma Lattes.
} 


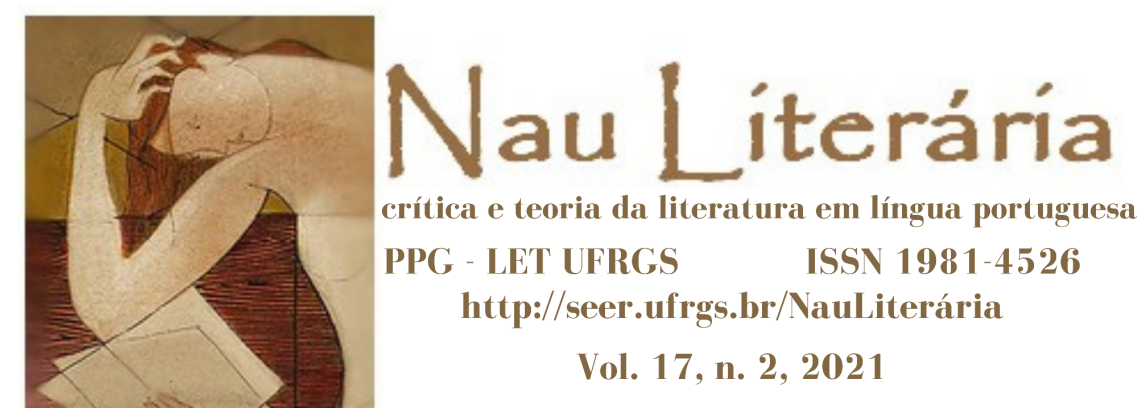

devido à simultaneidade de diferentes critérios de classificação, por outro lado, é rica de questionamentos.

Como efeito, além de crítica e teoria literária, há um movimento (talvez imprevisto) de metacrítica, em que o leitor é instigado a pensar sobre o estado atual da pesquisa acadêmica na área de literatura. Não se trata de ser seduzido por alguma teoria mais nova, mas de, a exemplo de Friedrich Nietzsche, perceber quais valores continuamos reproduzindo em nossos trabalhos como se fossem naturais. O questionamento dos fundamentos é uma prática saudável e desejável para a universidade, cuja relevância, cada vez mais, é posta à prova. Com seu discurso inquieto, repleto de perguntas sobre pesquisas alheias e principalmente sobre a própria, o texto de Chagas estreme o campo literário e convida os colegas a entrar no debate.

Seu interesse em investigar as transformações da década de 1970 não é recente, haja vista a tese de doutorado em filosofia, "1970”: arte e pensamento - mais uma mostra de sua metodologia interdisciplinar, ocupada mais de descrições do que de prognósticos, e que destaca nas relações observadas contingências em vez de necessidades. Ao cotejá-la com o livro que estamos resenhando, evidencia-se por que o pesquisador escolhe essa década como decisiva. 1970, segundo sua tese, marcaria o surgimento de uma episteme em oposição ao que ele, seguindo a nomenclatura de Friedrich Kittler, chama de 1800. Chagas descreve os dois paradigmas em termos de cultura, filosofia e ciência. Muitas dessas descrições referentes a 1970 lembram a abordagem pós-moderna, que também destaca o fim da universalidade explicativa. O pós-modernismo atribui isso à proliferação de diferenças identitárias, à fragmentação das narrativas no lugar da História com "h" maiúsculo, à hibridização cultural estimulada pela diáspora e pela globalização etc. (HALL, 2006). No entanto, o termo "pós-moderno" quase nunca é mencionado, o que nos leva a perguntar: por que o pesquisador mantém distância dessa linha teórica tão disseminada nas pesquisas sobre literatura contemporânea?

Ele próprio não explica isso em Todos eles romances, apenas não adere, como é direito de um pesquisador fazer suas escolhas metodológicas. Porém, em sua tese, encontramos uma 


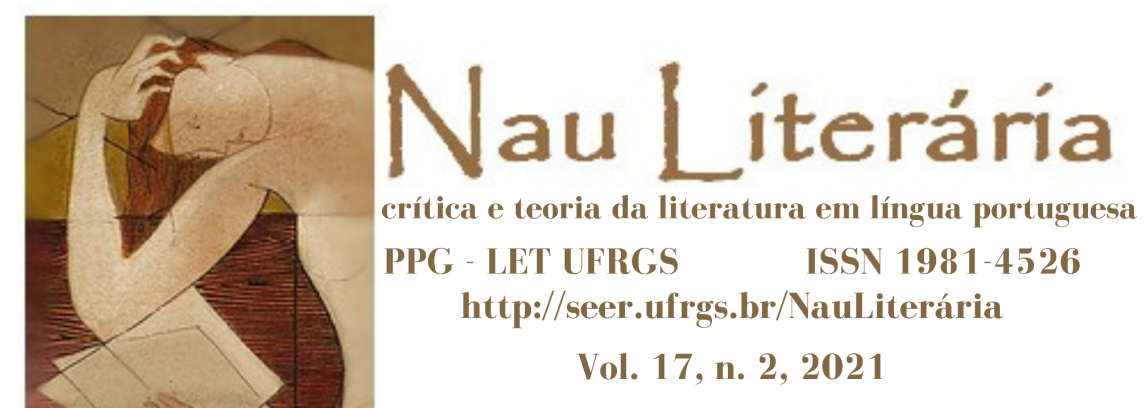

pista quando faz referência à "afoiteza [do pós-modernismo] em atribuir coerência à atualidade histórica" (CHAGAS, 2018, p. 178). Pressa e coerência são atributos diametralmente opostos ao trabalho de Chagas, que é vagaroso e centrífugo, transitando por uma grande quantidade de autores de diversas áreas do conhecimento sem tentar chegar a uma síntese explicativa.

Do mesmo modo que Luiz Costa Lima, seu ex-orientador no doutorado em letras, ele se afasta também de outras tendências bem difundidas na academia brasileira, como a desconstrução, "em sua absolutização do "texto", e os estudos culturais, "em sua ocupação política da lacuna funcional da literatura" (CHAGAS, 2018, p. 178). Prefere convocar um repertório diversificado, como os das ciências cognitivas, da antropologia evolutiva, das teorias da recepção etc., para situar a literatura em sua complexidade. O estudo do texto isolado não é um mal em si - o próprio Chagas faz várias de suas análises em close reading -; o problema é quando os estudos literários esquecem todos os demais agenciamentos que o circundam e atravessam, como se o texto estive imune a isso. Todos eles romances, em suma, descreve a complexidade da literatura brasileira contemporânea e, uma vez que nós a observamos, pode se tornar difícil ignorá-la em nossas próprias pesquisas. A sensação, ao concluir sua leitura densa, é de que há muita pesquisa a ser feita, nesta e em outras perspectivas teóricas, um estímulo bem-vindo contra a cegueira e o cansaço acadêmico.

\section{Referências}

BUENO, Luís. Uma história do romance de 30. São Paulo: Edusp; Campinas: Editora da Unicamp, 2006.

CHAGAS, Pedro Dolabela. Todos eles romances: a variação do gênero no Brasil, 1960-1980. Campinas: Editora da Unicamp, 2020. . “1970”: arte e pensamento. Belo Horizonte: Editora da UFMG, 2018. 


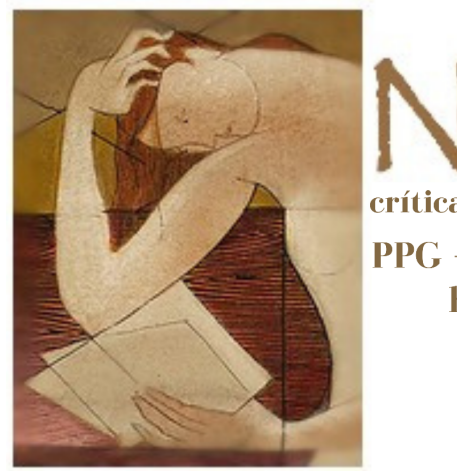

teoria da literatura em língua portuguesa

LET UFRGS ISSN 1981-4526

http://seer.uf rgs.br/NauLiterária

Vol. 17, n. 2, 2021

GUMBRECHT, Hans Ulrich. Depois de 1945: latência como origem do presente. Trad. Ana Isabel Soares. São Paulo: Editora da Unesp, 2014.

HALL, Stuart. A identidade cultural na pós-modernidade. Trad. Tomaz Tadeu da Silva; Guacira Lopes Souro. Rio de Janeiro: DP\&A, 2006. 